\title{
Spatial and temporal variability of snow depth and ablation rates in a small mountain catchment
}

\author{
T. Grünewald, M. Schirmer, R. Mott, and M. Lehning \\ WSL Institute for Snow and Avalanche Research SLF, 7260 Davos Dorf, Switzerland \\ Received: 22 December 2009 - Published in The Cryosphere Discuss.: 13 January 2010 \\ Revised: 2 May 2010 - Accepted: 10 May 2010 - Published: 28 May 2010
}

\begin{abstract}
The spatio-temporal variability of the mountain snow cover determines the avalanche danger, snow water storage, permafrost distribution and the local distribution of fauna and flora. Using a new type of terrestrial laser scanner, which is particularly suited for measurements of snow covered surfaces, snow depth was monitored in a high alpine catchment during an ablation period. From these measurements snow water equivalents and ablation rates were calculated. This allowed us for the first time to obtain a high resolution ( $2.5 \mathrm{~m}$ cell size) picture of spatial variability of the snow cover and its temporal development. A very high variability of the snow cover with snow depths between 0-9 $\mathrm{m}$ at the end of the accumulation season was observed. This variability decreased during the ablation phase, while the dominant snow deposition features remained intact. The average daily ablation rate was between $15 \mathrm{~mm} / \mathrm{d}$ snow water equivalent at the beginning of the ablation period and $30 \mathrm{~mm} / \mathrm{d}$ at the end. The spatial variation of ablation rates increased during the ablation season and could not be explained in a simple manner by geographical or meteorological parameters, which suggests significant lateral energy fluxes contributing to observed melt. It is qualitatively shown that the effect of the lateral energy transport must increase as the fraction of snow free surfaces increases during the ablation period.
\end{abstract}

\section{Introduction}

The largest part of annual winter precipitation in the Alps above $1000 \mathrm{~m}$ a.s.l. falls as snow. Most of this precipitation is stored in the snow cover until melting starts at the end of the accumulation season. The amount and timing of the melt strongly depend on the thickness and the spatial distribution

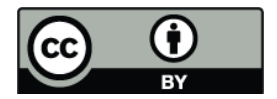

Correspondence to: T. Grünewald (gruenewald@slf.ch) of the snow cover. Hence the spatial and temporal variability of the snow cover greatly impacts the alpine water balance and strongly affects nature and mankind (Elder et al., 1998). Drinking water supplies, hydro-power, agriculture and vegetation growth, all strongly depend on snow cover and alpine water storage (Keller et al., 2000; Jones et al., 2001; Armstrong and Brown, 2008). Moreover rapid melting can cause flooding and increased erosion (e.g. Male and Gray, 1981; Pomeroy and Gray, 1995). Furthermore, winter tourism, with its high economic importance in many alpine regions, strongly depends on snow reliability and snow cover duration (e.g. Haefner et al., 1997; Beniston, 2000; Fazzini et al., 2004; López-Moreno and Nogués-Bravo, 2006; Marty, 2008).

To make reliable assessments of current and future snow dynamics, it is essential to obtain a better understanding of the total amount of snow stored in a catchment and how snow cover changes in space and time, especially in the ablation period.

A lot of work has been carried out on the spatial variability of snow depth and snow water equivalent $(S W E)$ and how it is influenced by meteorological and topographical factors on different scales (e.g. Blöschl, 1999; Balk and Elder, 2000; Liston and Sturm, 2002; Pomeroy et al., 2003; Deems et al., 2006; Trujillo et al., 2007; Mott et al., 2008; Merz et al., 2009; Dadic et al., 2010). In particular, snow deposition and snow transport due to wind have been investigated in great detail (e.g. Doorschot et al., 2001; Lehning et al., 2008) and it has been shown that snow distribution influences runoff dynamics in mountain catchments (Lehning et al., 2006). Many of these efforts, however, are based on model studies and insufficient validation measurements exist. Very often, limited snow depth and SWE observations are extrapolated to large areas using statistical models (e.g. Luce et al., 1999; Chang and Li, 2000; Marchand and Killingtveit, 2004; Erickson et al., 2005; López-Moreno and Nogués-Bravo, 2006; Bavera and De Michele, 2009).

Published by Copernicus Publications on behalf of the European Geosciences Union. 
LiDAR altimetry is a promising method to obtain areawide high resolution snow depth data. Airborne laser scanning $(A L S)$ proved to be an appropriate and accurate method for gathering area-wide snow depth measurements (Hopkinson et al., 2001; Deems and Painter, 2006). ALS data were used to investigate spatial variability and scale invariance of snow depth and its relationship to wind direction, vegetation and topography for several mountainous test sites (Deems et al. 2006; Trujillo et al. 2007).

In recent years, the introduction of terrestrial laser scanning $(T L S)$ to snow science has given a further push forward as this technology provides the possibility to obtain more cost effective and flexible area-wide snow depth observations with high spatial resolution (Bauer and Paar, 2004; Jörg et al., 2006; Prokop, 2008). Prokop et al. (2008) and Schaffhauser et al. (2008) performed detailed investigations on the accuracy of $T L S$ for measuring snow depth and showed that $T L S$ is an appropriate tool for mapping snow depth with high accuracy.

However, so far this promising technique has not been used to focus on snow depth distributions and their time development for a catchment. By performing repeated $T L S$ measurement campaigns in the Albertibach-catchment (Davos, Switzerland) during the entire ablation season of winter 2007/08, we present a unique data set of snow depth and $S W E$ variability in a high mountain setting. The repeated catchment-wide measurement campaigns offer the possibility to investigate seasonal snow cover changes by investigating snow depth changes (mostly depletion) during the ablation phase.

This paper presents a first qualitative and quantitative investigation of this dataset. We first give an overview of the study site and the methods used for collecting, processing and analysing the data. Then the spatial and temporal development of snow depth and $S W E$ are analysed, followed by a detailed description of the ablation rates and an investigation of statistical correlations with weather and terrain parameters. Finally, conclusions of the main results of the study and a short outlook on future tasks and challenges are presented.

\section{Method and data}

\subsection{Site description}

The area of investigation is a small mountain catchment located in the region of Davos, Switzerland (Fig. 1). The area of interest is defined by the drainage area of the Albertibach, which discharges in an easterly direction and is surrounded by steep mountain ridges to the north and south. The elevation of the area ranges from 1940 to $2658 \mathrm{~m}$ a.s.l. and is located above the local tree line. The total size of the catchment area is $1.3 \mathrm{~km}^{2}$, of which we covered $0.6 \mathrm{~km}^{2}(46 \%)$ in the laser surveys. The scanned area can be regarded as representative for the entire catchment in terms of elevation

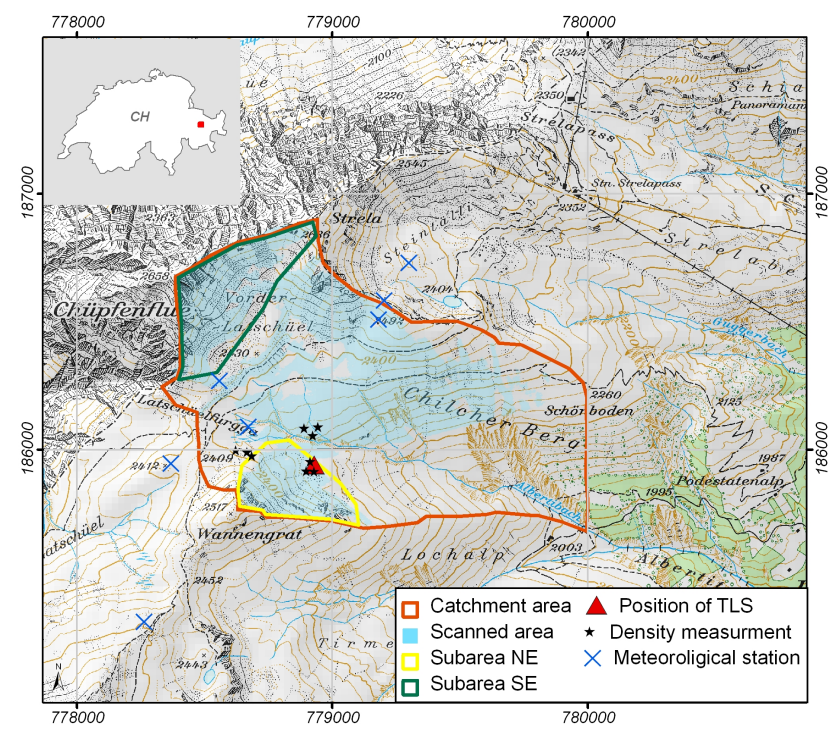

Fig. 1. Location of the Albertibach catchment (marked with the red line), the sub-areas $N E$ (yellow line) and $S E$ (green line), the area scanned in the TLS surveys (blue), the position of the TLS (red triangle) and of the meteorological stations in the area (blue crosses). Black stars indicate the position of the density samples taken at 26 April 2008. (base map: Pixelkarte PK25 @ 2009 swisstopo (dv033492))

range, aspect, and slope. The site is well equipped with a dense network of seven meteorological stations, which provide continuous meteorological data.

\section{Measurement methodology and accuracy assessment}

We carried out four measuring campaigns to collect the data used in this study during the winter 2007/08. Surveys were made at the end of the accumulation season (26 April 2008) and at intervals of about two weeks until the end of the melting season (13 May, 2 June and 10 June). The end of the accumulation season was estimated from snow depth measurements at the permanent weather stations in the catchment.

To investigate area-wide snow depth, we used a Riegl LPM 321 terrestrial laser scanner (Riegl, 2008). With a wavelength of $905 \mathrm{~nm}$, the $L P M 321$ operates in a wavelength where the reflectivity of snow is very high. The $L P M$ was mounted on a mobile tripod, which was placed on a small hill located in the south of the investigation area (Fig. 1). This position was chosen as it provides good angles of incidence for the scanner for most areas of interest and a good overall coverage of the catchment. Additionally, the place is easily accessible from the nearby storage place of the scanning equipment. In order to minimize possible errors which might be caused by slight settling or tilting of the tripod, the area was sub-divided into five single scans. Each of the scans was restricted to a maximum duration of one hour and the 
position of the instrument was re-determined after each scan. Detailed information how to measure snow depth with $T L S$ can be found in Prokop (2008).

We subjected all laser data to a variety of quality checks. In particular, we compared the laser measurements with those obtained from a tachymeter, as described in Prokop et al. (2008). With a tachymeter (Leica TCRP1201 total station) more than 500 single distance measurements were obtained on each of the four measurement campaigns. The tachymeter provided a very high accuracy for distance measurements at mid-range distances (up to $300 \mathrm{~m}$ ) and therefore provided an adequate method for the quality assessment (Prokop et al., 2008). The quality control revealed that snow depths showed mean deviations in the z-direction of less than $4 \mathrm{~cm}$ and standard deviations of less than $5 \mathrm{~cm}$ for distances of up to $250 \mathrm{~m}$. This is a higher level of accuracy than that published by Prokop et al. (2008) and more than sufficient for our purposes.

Furthermore, an airborne laser scan is available for the end of the accumulation season using an independent helicopter based technology (Vallet et al., 2005; Skaloud et al., 2006). With this data, it was possible to investigate whether there were systematic errors in the terrestrial scans. The analysis showed that the $A L S$ data had a mean deviation of less than $5 \mathrm{~cm}$ compared to a simultaneously performed tachymeter survey. The standard deviation was $6 \mathrm{~cm}$. The spatial distribution of the deviation in z-direction between the $A L S$ and the $T L S$ survey for 26 April is shown in Fig. 2. Comparing $T L S$ and $A L S$ gave a mean deviation of $10 \mathrm{~cm}$ and a standard deviation of $13 \mathrm{~cm}$. The difference between $T L S$ and $A L S$ increased with the distance measured by the $T L S$ as clearly visible in Fig. 2 (blue colours). This is likely due to a decrease in accuracy of the $T L S$ over long distances as the footprint of the laser beam increases. Furthermore, small deviations from the accurate position of the scanner's origin have a larger influence at larger distances. Especially in the areas with big differences between $A L S$ and $T L S$, angles of incidence were worse for the $T L S$, which again affects the accuracy of the scan. The positive deviations (yellow and red areas in the east of the investigation area) were probably caused by a marginal movement or settling of the tripod, which caused a slight disposal of the $T L S$ in comparison to the $A L S$ for that area. Nevertheless the accuracy of the $T L S$ is still more than sufficient for the analysis presented here.

\subsection{Data processing}

$T L S$ measures the point distances from the scanner to the surface of the targets (snow surface) with high spatial resolution and accuracy. To get absolute snow depths, the scans must be subtracted from a digital elevation model (DEM). The DEM used in this study was created from a summer $T L S$ survey using the same technology. A cell-size of $2.5 \mathrm{~m}$ was chosen for the $D E M$ and for the resulting snow depth maps.

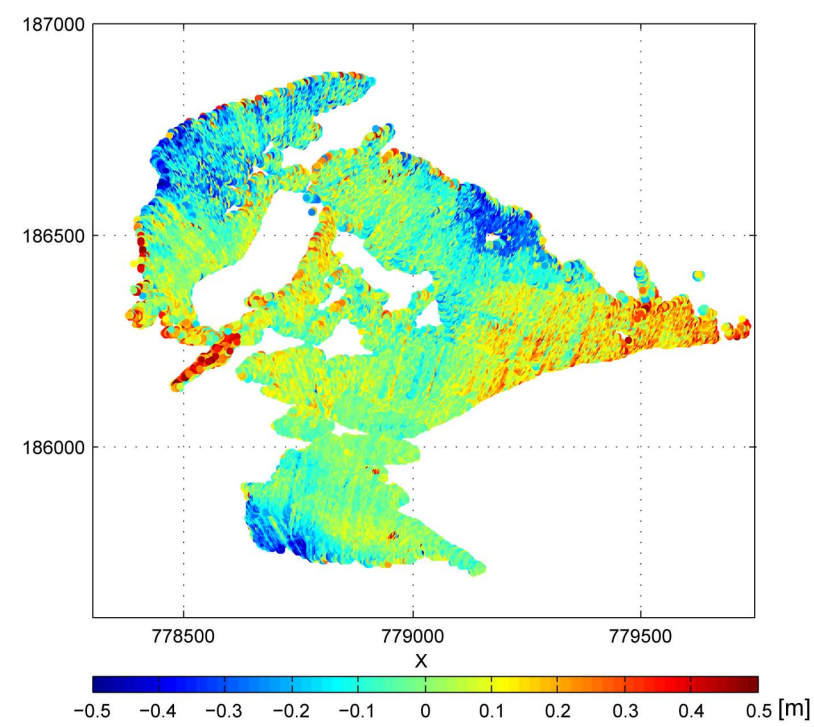

Fig. 2. Spatial distribution of the deviation in z-direction [m] between $A L S$ and $T L S$ survey for 26 April 2008.

To calculate $S W E$ and ablation rates from snow depth data, average snow cover density estimations are necessary. Many studies have found that the spatial variability of density is relatively small in comparison to snow depth (e.g. Dickinson and Whiteley, 1972; Pomeroy and Gray, 1995; Marchand and Killingtveit, 2004; Mizukami and Perica, 2008). Consequently, it is common to estimate areal $S W E$ with a small number of representative density measurements and a high number of snow depth data (e.g. Rovansek et al., 1993; Elder et al., 1998; Jonas et al., 2009). Thus, we calculated $S W E$ based on a small number of well selected density measurements. Depth-average snow density is often assumed to be controlled by a small number of topographical and meteorological parameters which are total snow depth, elevation, solar radiation, climatic region and vegetation patterns (e.g. Anderton et al., 2004; Jonas et al., 2009). Because of the limited extent of the investigation area, we only focus on snow depth and solar radiation in this study.

To ascertain whether there was a significant dependency between the snow density $(\rho)$ and solar radiation, we classified the investigation area into three sub-areas using total potential incoming solar radiation for the particular time periods between two investigations, as simulated with the physical based model Alpine3D (Lehning et al., 2006; Helbig et al., 2009). For each radiation class, we took three manual $S W E$-measurements at locations with different snow depths $(H S)(<0.5 \mathrm{~m}, 0.5-1.0 \mathrm{~m},>1.0 \mathrm{~m})$. The locations of the measurements carried out on 26 April are shown in Fig. 1. Thus we could obtain a depth dependent average density, $\rho(R, t)$, for each radiation class $(R)$ and each time step $(t)$. To test the significance of the dependencies $\rho(R)$ and $\rho(t)$ we used the Kruskal-Wallis test. The tests showed that there were 
Table 1. Depth-averaged snow density values $\rho(t) \frac{\mathrm{kg}}{\mathrm{m}^{3}}$ for each time step, standard deviation $\sigma(\rho(t))$ and number of samples $(n)$.

\begin{tabular}{lcccc}
\hline & 26 Apr & 13 May & 2 Jun & 10 Jun \\
\hline$\rho(t)$ & 342 & 389 & 477 & 501 \\
$\sigma(\rho(t))$ & 29 & 24 & 65 & 34 \\
$n$ & 9 & 9 & 9 & 9 \\
\hline
\end{tabular}

significant differences for the specific time steps $(t)$ but no significant dependency on radiation classes $R(t)$. We also investigated if a direct relationship between $H S$ and $\rho(t)$ was obvious from the measurements but no general trend could be found. We hence decided to use a single $\rho(t)$ for each time step which translates snow depth to $S W E$ :

$S W E=\rho(t) H S$

where $S W E$ is in mm and $H S$ in m. A summary of the calculated $\rho(t)$ values is given in Table 1 .

As a next step, we produced maps with the total SWE applying Eq. 1 to each of the four snow depth maps. Maps of the average daily "ablation rate" were created by calculating daily ablation rates from the change between two consecutive $S W E$ maps. The so called ablation rate can include contributions from snow falls, settling, snow transport, snow sublimation and true melting. As the $S W E$ maps are the results of a simple linear relationship as given in Eq. (1), the patterns of the snow depth maps and the SWE maps are identical for each single time step. Hence we will focus our analysis on snow depth maps only and give the values for $S W E$ in brackets where appropriate. Since $\rho$ is time dependent, the ablation rate and snow depth change maps did not show exactly the same patterns. But as there were no relevant differences in the characteristic features we focus on the results obtained from the daily ablation rates in what follows.

To refine the analysis, we separated two sub-areas from the investigation area (Fig. 1) based on the visual impression that two different snow distribution patterns may dominate these two sub-areas (Fig. 3): The first covers the north-easterly exposed slopes of Wannengrat, and will be referred to as $N E$ in the following. It is characterized by a highly variable snow deposition on a rather large scale. The second sub-area consists of the southeast-facing slopes of the Vordere Latschüel $(S E)$, which appears to have a rather homogeneous snow distribution.

\subsection{Data analysis}

A quantitative analysis of the raster maps allowed a detailed evaluation of the spatial and temporal variability of snow depth and the average ablation rates. We first visually interpreted the maps to identify obvious surface structures and characteristics. To quantify the spatial variability and changes in time, histogram plots for the distribution of snow depth (Figs. 5a, 6) and the average ablation rates (Fig. 9) between the individual scans were examined. Furthermore, we investigated basic statistics such as mean $(\mu)$, standard deviation $(\sigma)$ and total snow volume for each time period. For snow depth $\mu$ and $\sigma$ always refer to the area of the first survey (26 April), which is marked as "Scanned area" in Fig. 1. The histograms refer to the snow covered area of the respective survey.

For the daily ablation rates we only considered cells which still were snow covered on the second of two succeeding surveys. The snow covered area was determined with orthophotos, which were taken from a camera, which is an integral part of the TLS measurement set-up. We then focused on possible statistical dependencies of the ablation rate in the investigation area on topographic and meteorological parameters. For this purpose, the Pearson's linear correlation coefficient for the ablation rate as dependent variable was calculated (Fig. 10). As independent variables we used:

- Topographical parameters derived from the DEM: altitude, slope, northing (difference in degrees from north).

- Mean daily sum of incoming solar radiation, simulated with the physical based model Alpine $3 D$ (Lehning et al., 2006; Helbig et al., 2009), for each period of two succeeding surveys. As input data for the model, we used data derived from an automatic weather and snow station located in the catchment. The model then produced hourly output for incoming shortwave radiation for each grid-cell of a $10 \mathrm{~m}$-raster. We then averaged the output to one mean radiation day for each of the three periods.

- SWE at the end of the accumulation season $\left(S W E_{\max }\right)$ derived from the $T L S$ survey. The ablation rate as calculated here contains also the contribution of settling and we therefore also investigated whether a correlation between maximum snow depth or $S W E$ and ablation rate exists.

- Local windspeed obtained from high resolution flow fields, simulated with the mesoscale atmospheric model ARPS (Xue et al., 2000; Mott et al., 2008; Raderschall et al., 2008; Mott and Lehning, 2010). The threedimensional windspeed was modelled on a horizontal grid resolution of $5 \mathrm{~m}$. The local flow fields were calculated for a north-westerly (windspeed ${ }_{\mathrm{NW}}$ ) and a southeasterly wind (windspeed SE$_{\text {) }}$ ) situation, which were observed to be the predominant wind directions for the three periods between the scans. Note that for the first period both wind situations occurred but the northwesterly situation dominated. In contrast, in the second period, both prevailing wind directions occurred with a similar frequency. In the third period only northwesterly wind situations were observed. 

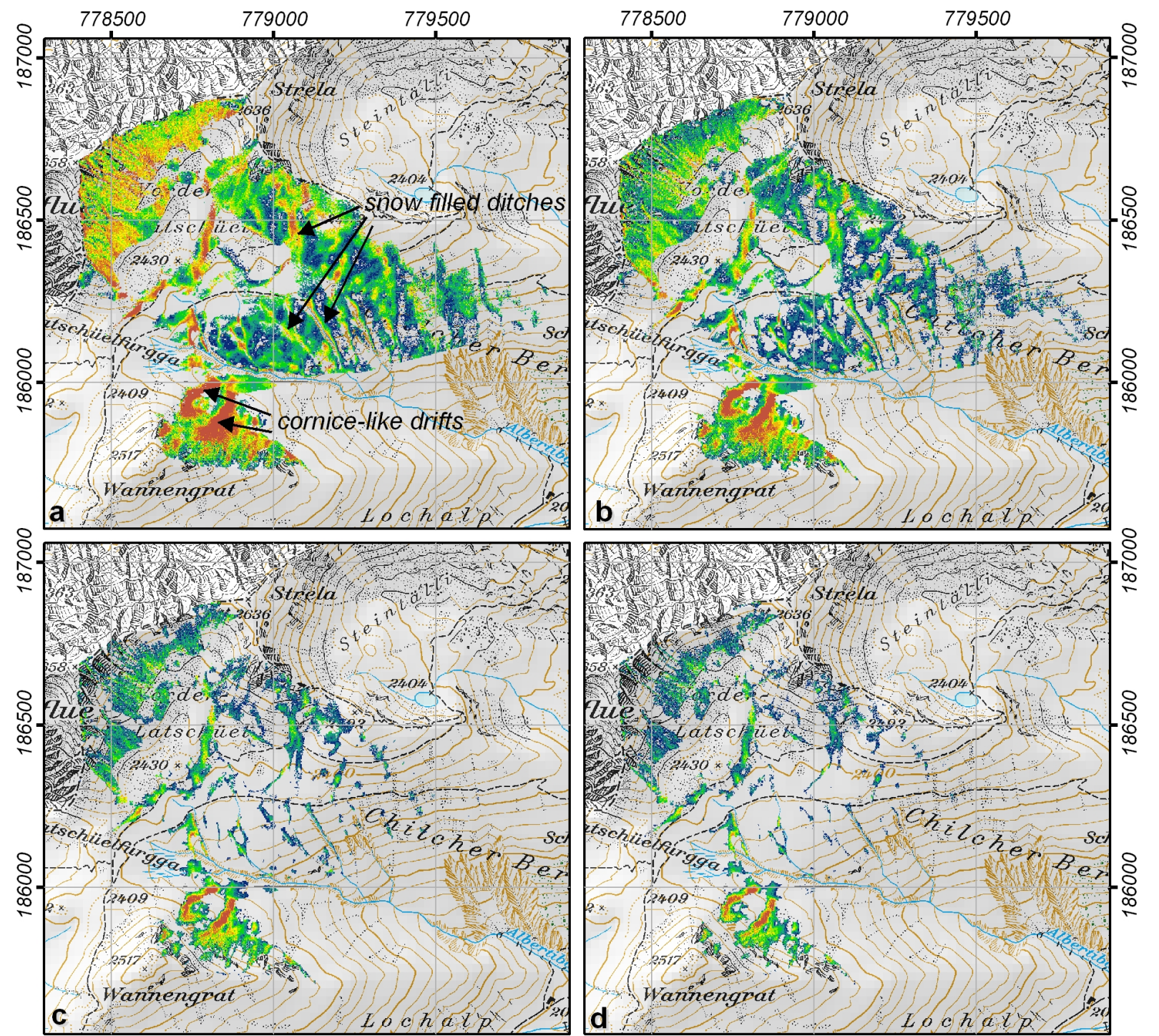

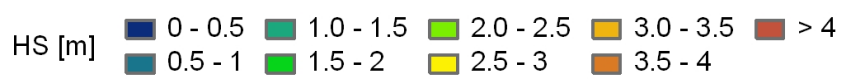

Fig. 3. Snow depth maps for 26 April (a), 13 May (b), 2 June (c) and 10 June (d). The black arrows mark examples for snow filled ditches and cornice-like drifts. (base map: Pixelkarte PK25 (C) 2009 swisstopo (dv033492)).

To account for possible interactions between these parameters, we combined the variables in multiple linear regression models allowing for interaction terms. Only the models which performed best will be shown in the following.

\section{Results and discussion}

\subsection{Time development of snow depth distribution}

A map of the spatial snow depth distribution in the investigation area for the end of the accumulation season (26 April) is shown in Fig. 3a. The corresponding calculated SWE map is shown in Fig. 4. At that point in time, the entire catchment was snow covered, with exception of small snow-free patches in the steep rock faces in the south and north-west of the area. The average snow depth was $2.0 \mathrm{~m}(S W E 696 \mathrm{~mm})$ and maximum snow depth was $9.0 \mathrm{~m}$ (SWE $3120 \mathrm{~mm})$. Those large snow depths were mainly located at two cornice-like drifts which had formed on the steep north-easterly slopes of the Wannengrat summit due to drifting and blowing snow. Areas with above average snow depth could also be found in the steep south facing slopes $(S E)$. The flatter areas of the Chilcher Berg clearly showed average or below average snow depths. Nevertheless, linear features with above average snow depth are also clearly visible in that area. From the $D E M$ and a topographic map we could identify those features as ditches, which were packed with snow probably due to snow transport processes (Lehning et al., 2008). 


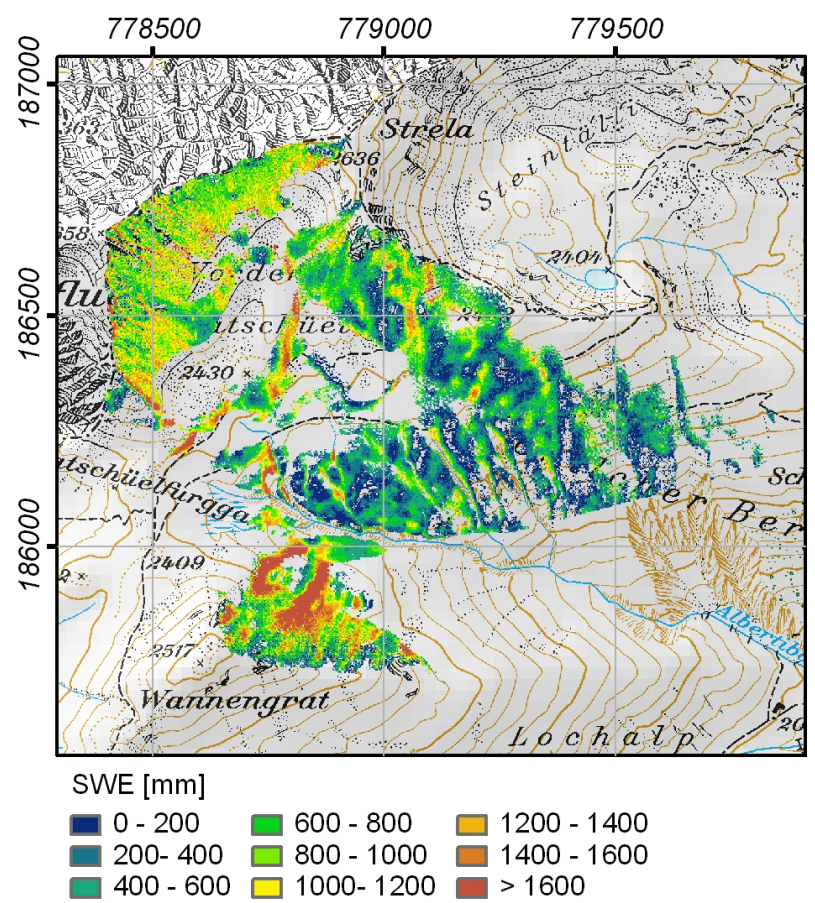

Fig. 4. SWE map for 26 April. (base map: Pixelkarte PK25 @ 2009 swisstopo (dv033492)).
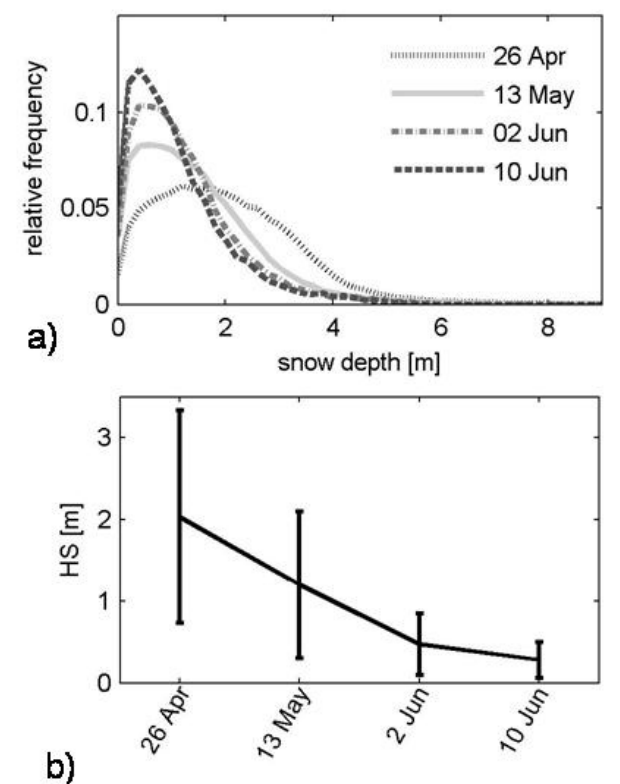

Fig. 5. (a) Histograms and statistics (b) of snow depth (HS) at the time of each scan. Only cells which were snow covered at the time of each scan are included to (a). Intervalsize 63. Statistics in (b) refer to the scanned area. The black line indicates the mean values and the error-bars the standard deviations.
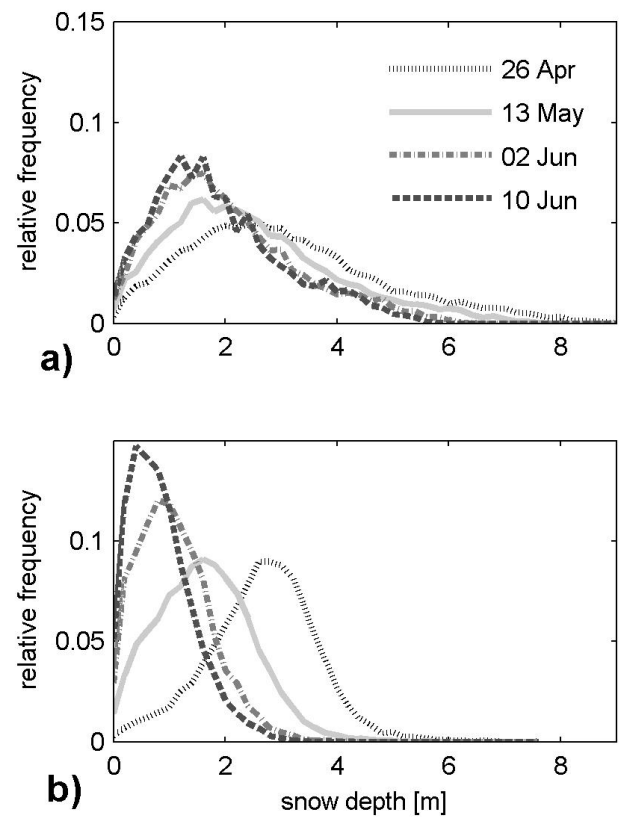

Fig. 6. Histograms of snow depth for the sub-areas $N E$ (a) and $S E$ (b). Interval size for (a): 63, interval size for (b): 53.

The following scan, 17 days later, showed predominantly unchanged spatial patterns (Fig. 3b): The cornice- like drifts in the $N E$ remained the dominant feature until the end of the ablation season while snow depth in the $S E$ suffered stronger decrease than average (Fig. 3c, d; see also Fig. 6). A significant number of snow-free patches emerged especially on the knolls and ridges where snow depth was lowest in the beginning of the ablation season. Complete melt out propagated quickly from those first snow-free areas. This may be because of lower snow depths at the edges of the snow patches or because of lateral advective transport of heat from the warmer snow-free surfaces onto the colder snow cover (Essery and Pomeroy, 2004), which will be discussed in detail below.

Histograms of snow depth at the time of each scan show that the distribution and the variability changed in the course of the ablation season (Fig. 5a). The mean snow depth and the spatial variability, represented by the standard deviation $(\sigma)$, both continuously decreased but $\sigma$ remained on a high level (Fig. 5b). More interestingly, the standard deviation of snow depth still decreased when calculated for the snow covered area only. In fact, the numerical value was almost identical to the one based on the total area with deviations less than $10 \%$.

The snow covered area and the total volume of SWE stored in the area strongly decreased. While $98 \%$ of the investigation area was covered with snow on 26 April, this area steadily decreased to $25 \%$ on 10 June (13 May $=82 \%$, 2 June $=38 \%$ ). The snow volume decreased from $3.3 \times 10^{5} \mathrm{~m}^{3}$ on 26 April to $1.0 \times 10^{5} \mathrm{~m}^{3}$ on 10 June $(13$ May $=2.6 \times 10^{5} \mathrm{~m}^{3}, 2$ June $=1.1 \times 10^{5} \mathrm{~m}^{3}$ ). 
There were clear differences in snow depth distribution between the two sub-areas $S E$ and $N E$ (Fig. 6a, b). The cornice-like drifts (discussed above), which featured the areas maximum snow depth, were located in $N E$. The mean snow depths with $3.1 \mathrm{~m}(S W E=1059 \mathrm{~mm})$ were therefore larger in the $N E$ than in the $S E$ with $2.7 \mathrm{~m}(S W E=919 \mathrm{~mm})$ at the end of the accumulation season. A higher variability was also observed in the $N E(\sigma=1.7 \mathrm{~m} / 569 \mathrm{~mm})$ than in the $S E(\sigma=1.0 \mathrm{~m} / 355 \mathrm{~mm})$. This finding is also obvious from Fig. 3, where the more homogenous snow depth values in the $S E$ are clearly visible. The context of higher variability and higher mean snow depth in the $N E$ remained during the entire ablation season.

\subsection{Spatio-temporal variability of ablation rates and their correlation with simple weather and terrain parameters}

Ablation rates (as $S W E$ ) are shown in Fig. 7 and the corresponding histograms are illustrated in Fig. 9 for all three investigation periods. For comparison, a map showing differences in snow depth is presented in Fig. 8. For the period from 26 April to 13 May the spatial differences in ablation rates with the highest rates in the steep south facing slopes and the lowest rates in the northern exposed slopes are clearly visible in Fig. 7a and represent the distribution of potential radiation. The average ablation rate was $15 \mathrm{~mm} / \mathrm{d}(\sigma=7 \mathrm{~mm} / \mathrm{d})$ for this period, increasing to $16 \mathrm{~mm} / \mathrm{d}$ $(\sigma=7 \mathrm{~mm} / \mathrm{d})$ for the second and $30 \mathrm{~mm} / \mathrm{d}(\sigma=12 \mathrm{~mm} / \mathrm{d})$ for the last period (Fig. 9). This increase can easily be explained by the larger amount of energy, in the form of incoming solar radiation, available for melting later in the hydrological season. It has to be noticed that no distinct change occurred between the first and the second period due to cool and moist weather during the second period. However, both $\mu$ and $\sigma$ strongly increased in the last period. While the spatial variability of snow depth decreased (Figs. 3 and 5), the spatial variability of the ablation rates increased with time (Figs. 7 and 9).

Similar to the study of Anderton et al. (2004), we could only identify weak correlations between ablation rates and relevant topographic and meteorological parameters. Pearson's linear correlation coefficients are shown in Fig. 10 for all parameters and each time interval: Altitude, slope, northing (each $r=0.4)$, solar radiation $(r=0.3)$ and windspeed $_{\mathrm{SE}}(r=0.3)$ provided the best correlations for the first period (26 April-13 May).

Note that the high correlation with slope, meaning that flat areas are characterised by smaller ablation rates, cannot be explained by relocation of snow from steep to flat areas due to avalanches, as no avalanches occurred during the ablation season.

For the second period (13 May -2 June) all high correlations from the first period decreased (slope: $r=0.2$, altitude, northing each $r=0.1$, radiation $r=-0.1$, wind- speed $\left._{\mathrm{SE}}=0.2\right)$ whereas $S W E_{\max }$ gave the best correlation with $r=-0.4$. In the final period ( 2 June-10 June) all correlations became very weak. This finding with the better correlations resulting from different parameters in comparison to period one, again suggests that the factors which dominate melt change in time. The strong decrease of the correlation is in this context attributed to the rising heterogeneity of the surface and of its energy balance which we already described above. The later in the ablation season, the smaller the direct influence of the parameters and the more "random" the ablation pattern appears. It is important to note that the ablation pattern is not really random but determined by the distribution of snow free patches in the vicinity, which is not represented in local correlations. A further surprising outcome is the decrease of the correlation coefficient for windspeed ${ }_{\mathrm{SE}}$ although a major foehn event occurred in the second period. Local high windspeeds promote turbulent fluxes and therefore affect the local energy balance. But advective effects as discussed below would not show up in such a local analysis and require a more involved analysis, which we plan to carry out in future.

The weak correlations become even clearer when analysing the scatterplots of the ablation rates against the predicting parameters. A scatter plot of ablation rates against incoming solar radiation is shown in Fig. 11. The large scattering of the data clearly illustrates that high statistical correlations cannot be expected from these data.

These findings lead to the conclusion that none of the simple univariate parameters was adequate to explain spatial ablation characteristics to a satisfactory degree. A possible additional factor other than lateral energy transport discussed below may be that the spatial resolution of $2.5 \mathrm{~m}$ may still be too coarse. Windspeed was modelled on a spatial resolution of $5 \mathrm{~m}$. A smaller horizontal resolution would strongly influence the local windspeed distribution (Mott and Lehning, 2010). Patterns which were caused by the micro-relief are not captured by that resolution. Furthermore, there may be differences between the modelled meteorological variables and the true distribution, e.g. incoming radiation neglects frequent convective clouds over mountain tops.

To examine if interactions between the topographical and meteorological parameters might play a role, we built several multiple linear regression models, for which we tested different factor combinations. For the construction of the regression models, the variables were scaled linearly to $[-1 ; 1]$, to allow a direct comparison of the coefficients. Similar to the univariate correlation analysis, different models performed best for the individual periods: The best fit for the first period is given in Eq. 2 and resulted in an $R^{2}$ of 0.4. Additional factors and factor combinations could not significantly improve the fit. 

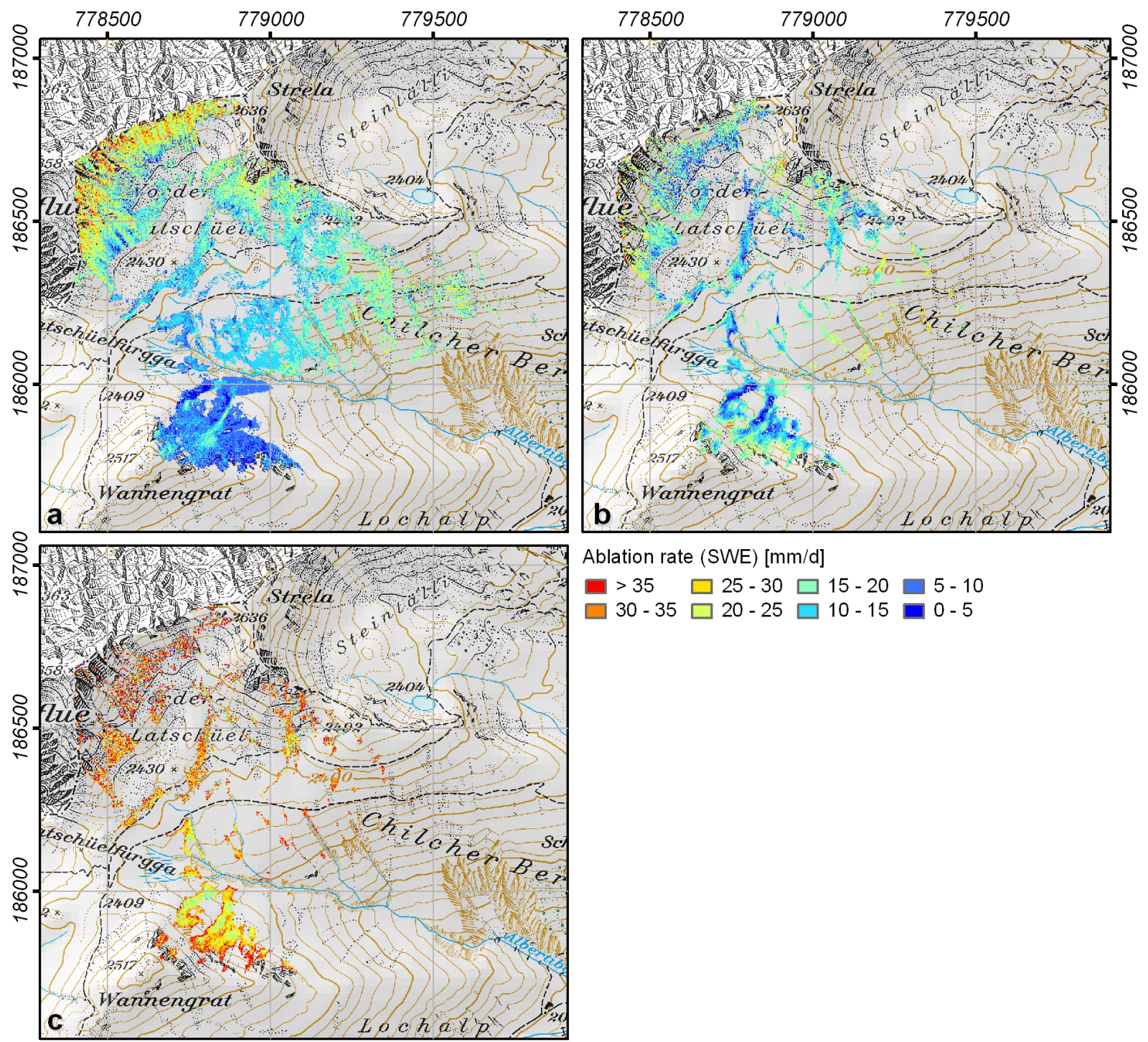

Fig. 7. Daily ablation rates (SWE) averaged for the time periods 26 April-13 May (a), 13 May-2 June (b) and 2 June-10 June (c). (base map: Pixelkarte PK25 (C) 2009 swisstopo (dv033492)).

$$
\begin{aligned}
\text { rate }_{1} & =4.2 \cdot \text { altitude }+7.6 \cdot \text { slope }+5.6 \cdot \text { northing } \\
& +3.8 \cdot \text { radiation }+12.2
\end{aligned}
$$

For the second period an $R^{2}$ of 0.3 was obtained from the model described in Eq. 3. Most variables which performed best in linear correlation analysis were also showing up in the multiple regression models, but in slightly different order. Slope was the most important variable in Eq. 2 and $S W E_{\max }$ accounted for the highest coefficient in Eq. 3.

$$
\begin{aligned}
\text { rate }_{2} & =-2.1 \cdot \text { altitude }-8.8 \cdot \text { slope }-13.6 \cdot S W E_{\max } \\
& +7.9 \cdot \text { windspeed }_{\mathrm{NW}}+18.2
\end{aligned}
$$

The last period did not give significant correlations. As has already been seen in the univariate correlations, we could ob- serve a decrease in correlation with time and this was confirmed by the multiple regressions. Therefore, the influence of topography and meteorology on ablation rates gets consistently weaker later in the ablation season. Using f-test, all regressions were found to be highly significant $(p<0.001)$ which is not surprising when taking the large size of the sample $(\mathrm{N}>18000)$ into account.

It can be concluded that the spatial distribution of the ablation rates appeared to be quite random and only week correlations with local topographic factors could be detected. The observed temporal change in variability and spatial patterns, in particular for the last period, might be explained by a shift of the dominating processes which had an impact on the melting: In the first period, the energy available for melting was dominated by shortwave radiation, which is also indicated by the relatively strong correlation coefficient for 


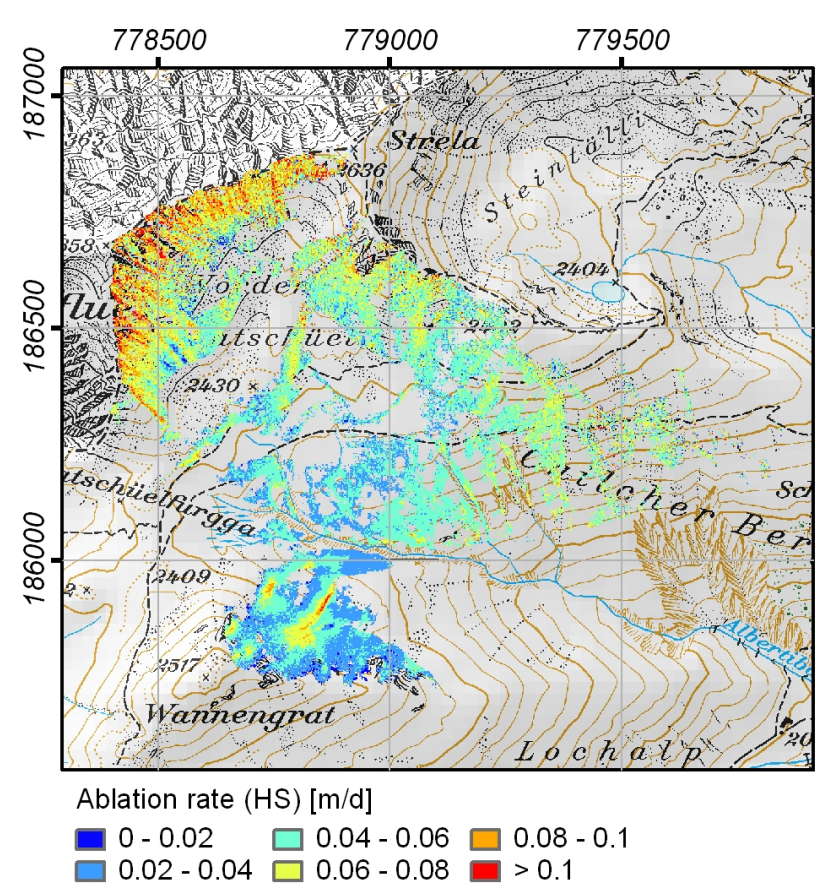

Fig. 8. Daily ablation rate in snow depth $(H S)$ averaged for the time periods 26 April-13 May. (base map: Pixelkarte PK25 (C) 2009 swisstopo (dv033492).

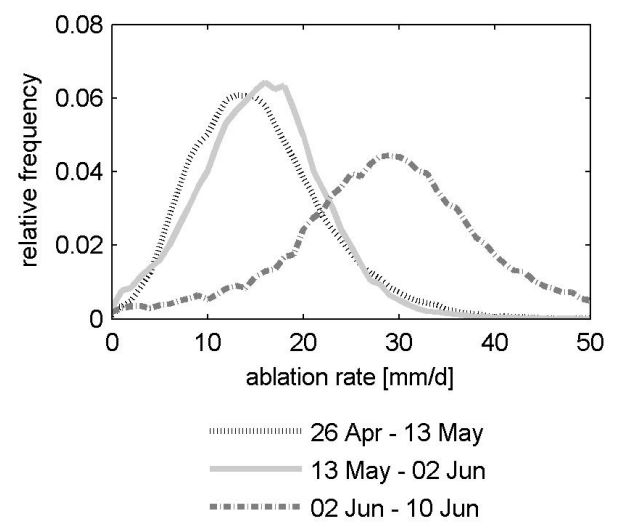

Fig. 9. Histograms of daily ablation rate (SWE). Interval size: 124.

shortwave radiation $(r=0.3)$ described above. Later in the hydrological season the rapidly increasing fraction of snow free areas leads to changes in the energy balance: The surface albedo of snow free patches is small and causes higher surface temperatures and higher values of lateral sensible heat fluxes and longwave radiation, which then lead to increased melting of the surrounding snow patches (Essery and Pomeroy, 2004) especially at the edges of the patches. Thus, big differences in melting between small and larger snow patches may occur. Nonetheless, a comparison of coefficient of variation values $(C V=\sigma / \mu)$ showed that the spatial variability of the ablation rates with $C V$ - values of $0.4-0.5$ was lower than the spatial variability of snow depth and $S W E$

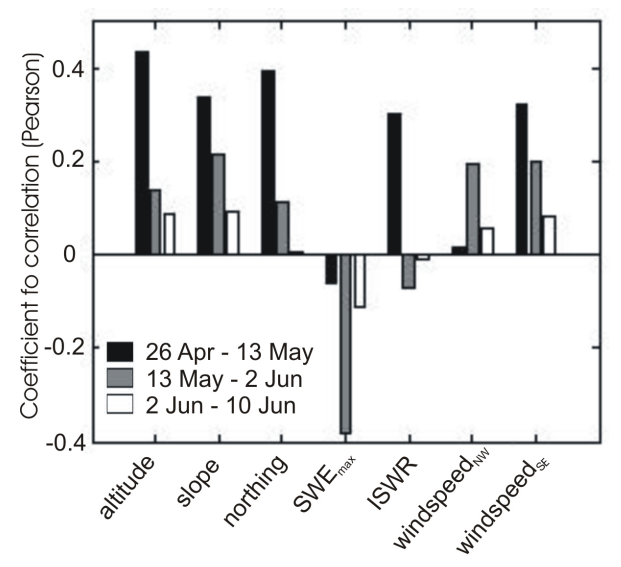

Fig. 10. Coefficient of correlation (Pearson) for daily ablation rates for each time period against altitude, slope, northing, SWE at the end of the accumulation season $\left(S W E_{\max }\right)$, incoming shortwave radiation for each period (ISWR) and windspeed for prevailing wind direction north-west (windspeed $\mathrm{NW}_{\mathrm{NW}}$ ) and south-west (windspeed $\left._{\mathrm{SW}}\right)$.

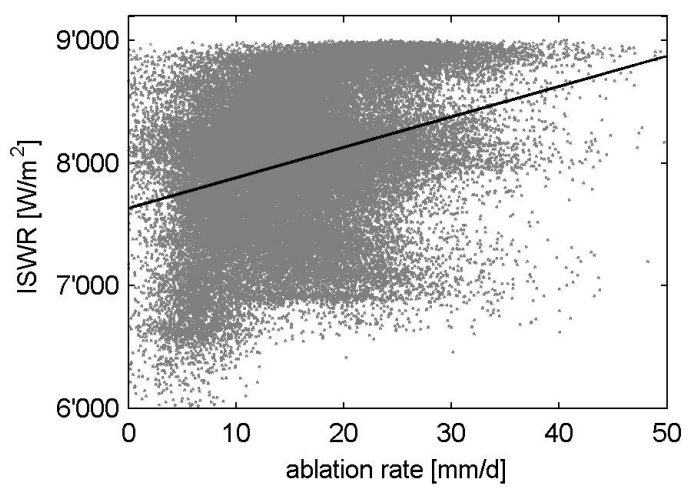

Fig. 11. Scatterplot of $S W E$ ablation rates (26 April-13 May) and mean daily sum of incoming shortwave radiation (ISWR). The solid line draws the linear fit function derived from the univariate regression analysis.

$(C V=0.6-2.0)$, even for the latest time period, where the scatter in ablation rates was largest. As can be seen in Fig. 3, as a consequence, the relatively low variability of the ablation rates cannot substantially alter the spatial structure of snow depth and $S W E$, which was determined during the accumulation season. As an example, both pronounced accumulation zones in sub-area $N E$ remained visible for the whole period of investigation. Thus, the effects of spatially variable melting on snow depletion are smaller than the effect of the snow distribution at the end of the accumulation season. Snow remains there, where most snow was accumulated during the accumulation season. This interpretation is consistent with the findings of Anderton et al. (2004), who stated that spatial patterns of snow disappearance were largely determined by the distribution of $S W E$ at the start of the melt season, rather than by spatial variability in ablation rates during the 
melt season. Their results based on manual surveys are now confirmed by our more detailed dataset.

\section{Conclusions}

First results from an extensive data set on the spatio-temporal variability of snow depth were presented. The main focus of the analysis was on snow depth distribution but values for $S W E$ were given where appropriate. We also present maps of the temporal changes of $S W E$, which are named "ablation rate" maps, although they are strictly the sum of real melt, sublimation and occasional smaller snowfalls.

Quality checks of the TLS measurement system against independent tachymeter and $A L S$ measurements showed good accuracy of the snow depth measurements such that the analysis presented appeared not to be limited by measurement problems.

The results showed that spatial distribution and the variability of snow depth remained similar for the whole ablation season. A striking result from the analysis of $S W E$ development during the ablation phase is that a very variable distribution of ablation rates was observed. We conclude that advective transport of melt energy from snow free areas to remaining snow patches was a major source for this variability and led to accelerated melt in the course of the ablation period in agreement with earlier results, which have been based on theoretical considerations (Essery and Pomeroy, 2004). This conclusion is consistent with the observation that initial weak correlations of ablation rates with obvious meteorological and local terrain parameters became even weaker towards the end of the ablation period.

Beyond the first analysis presented here, the data set allows significant further and more in depth work, which we are currently undertaking. A major effort is devoted to a more quantitative understanding of lateral energy transport discussed above by using a combination of a meteorological with a detailed surface process model (ARPS/Alpine3D). The most direct application is an assessment of total snow water storage as compared to interpolations made from flat field snow stations (e.g. Bocchiola et al., 2008; Janetti et al. 2008 ) and the validation of snow deposition and snow transport models (Lehning et al., 2008). A further interesting aspect is the development of surface roughness as a function of the variable snow cover.

Acknowledgements. We thank all people who helped during the extensive field work and in data processing. Part of the work has been funded by the Swiss National Science Foundation and the European Community. This work would not have been possible without all colleagues from SLF who contributed to this work in various ways. For proofreading special thanks go to Alec van Herwijnen. We finally thank our three reviewers, Ruzica Dadic, Juraj Parajka and Davide Bavera for their constructive comments and corrections.

Edited by: D. Hall

\section{References}

Anderton, S. P., White, S. M., and Alvera, B.: Evaluation of spatial variability in snow water equivalent for a high mountain catchment, Hydrol. Process., 18, 435-453, 2004.

Armstrong, R. L. and Brown, R.: Introduction, in: Snow and Climate, edited by: Armstrong, R. L. and Brun, E., Cambridge University Press, Cambridge, 1-11, 2008.

Balk, B. and Elder, K.: Combining binary decision tree and geostatistical methods to estimate snow distribution in a mountain watershed, Water Resour. Res., 36, 13-26, 2000.

Bauer, A. and Paar, G.: Monitoring von Schneehöhen mittels terrestrischem Laserscanner zur Risikoanalyse von Lawinen, 14th International Course on Engineering Surveying, Zürich, 1519 March 2004, 2004.

Bavera, D. and De Michele, C.: Snow water equivalent estimation in the Mallero basin using snow gauge data and MODIS images and fieldwork validation, Hydrol. Process., 23, 1961-1972, doi:10.1002/hyp.7328, 2009.

Beniston, M.: Environmental Change in Mountains and Uplands, London UK and Oxford University Press, New York, 172 p., 2000.

Blöschl, G.: Scaling issues in snow hydrology, Hydrol. Process., 13, 2149-2175, 1999.

Chang, K. T. and Li, Z.: Modelling snow accumulation with a geographic information system, Int. J. Geogr. Inf. Sci., 14, 693-707, 2000.

Bocchiola, D., Bianchi Janetti, E., Gorni, E., Marty, C., and Sovilla, B.: Regional evaluation of three day snow depth for avalanche hazard mapping in Switzerland, Nat. Hazards Earth Syst. Sci., 8, 685-705, doi:10.5194/nhess-8-685-2008, 2008.

Dadic, R., Mott, R., Lehning, M., and Burlando, P.: Wind Influence on Snow Depth Distribution and Accumulation over Glaciers, J. Geophys. Res., 115, F01012, doi:10.1029/2009jf001261, 2010.

Deems, J. S., Fassnacht, S. R., and Elder, K. J. Fractal Distribution of Snow Depth from Lidar Data, J. Hydromet., 7, 285-297, 2006.

Deems, J. S. and Painter, T. H.: Lidar measurement of snow depth: Accuracy and error sources, in: Proceedings of the International Snow Science Workshop ISSW, Telluride, CO, USA, 1-6 October 2006, 384-391, 2006.

Dickinson, W. T. and Whiteley, H. R.: A sampling scheme for shallow snow packs, Bulletin of the International Assosiation of Hydrological Sciences, 16, 247-258, 1972.

Doorschot, J., Raderschall, N., and Lehning, M.: Measurements and one-dimensional model calculations of snow transport over a mountain ridge, Ann. Glaciol., 32, 53-158, 2001.

Elder, K., Rosenthal, W., and Davis, R. E.: Estimating the spatial distribution of snow water equivalence in a montane watershed, Hydrol. Process., 12, 1793-1808, 1998.

Erickson, T. A., Williams, M. W., and Winstral, A.: Persistence of topographic controls on the spatial distribution of snow in rugged mountain terrain, Colorado, United States, Water Resour. Res., 41, W04014 doi:10.1029/2003WR002973, 2005.

Essery, R. and Pomeroy, J.: Implications of spatial distributions of snow mass and melt rate for snow-cover depletion: theoretical considerations, Ann. Glaciol., 38, 261-265, 2004.

Fazzini, M., Fratianni, S., Biancotti, A., and Billi, P.: Skiability conditions in several skiing complexes on Piedmontese and Dolomitic Alps, Meteorologische Zeitschrift, 13, 253-258, 2004. 
Haefner, H., Seidel, K., and Ehrler, H.: Applications of snow cover mapping in high mountain regions, Phys. Chem. Earth, 22, 275278, 1997.

Helbig, N., Löwe, H., and Lehning, M.: Radiosity Approach for the Shortwave Surface Radiation Balance in Complex Terrain, J. Atmos. Sci., 66, 2900-2912, 2009.

Hopkinson, C., Sitar, M., Chasmer, L., Gynan, C., Agro, D., Enter, R., Foster, J., Heels, N., Hoffnan, C., Nillson, J., and St.Pierre, R.: Mapping the Spatial Distribution of Snowpack Depth Beneath a Variable Forest Canopy using Airborne Laser Altimetry, Proceedings of the 58th Eastern Snow Conference, 17-19 May 2001, Ottawa, Ontario, Canada, 2001.

Janetti, E. B., Gorni, E., Sovilla, B., and Bocchiola, D.: Regional snow-depth estimates for avalanche calculations using a twodimensional model with snow entrainment, Ann. Glaciol., 49, 63-70, 2008.

Jonas, T., Marty, C., and Magnusson, J.: Estimating the snow water equivalent from snow depth measurements in the Swiss Alps, J. Hydrol., 378, 161-167, 2009.

Jones, H. G., Pomeroy, J. W., Walker, D. A., and Hoham, R. W.: Snow ecology: An interdisciplinary examination of snowcovered ecosystems, Cambridge University Press, Cambridge, UK, 378 pp, 2001.

Jörg, P., Fromm, R., Sailer, R., and Schaffhauser, A.: Measuring snow depth with a terrestrial laser ranging system, Proceedings International Snow Science Workshop ISSW 2006, Telluride, CO, USA, 1-6 October 2006, 452-460, 2006.

Keller, F., Kinast, F., and Beniston, M.: Evidence of the response of vegetation to environmental change at high elevation sites in the Swiss Alps, Regional Env. Change, 1, 70-77, 2000.

Lehning, M., Völksch, I., Gustafsson, D., Nguyen, T. A., Stähli, M., and Zappa, M.: Alpine3d: A detailed model of mountain surface processes and its application to snow hydrology, Hydrol. Process., 20, 2111-2128, 2006.

Lehning, M., Löwe, H., Ryser, M., and Radschall, N.: Inhomogeneous precipitation distribution and snow transport in steep terrain, Water Resour. Res., 44, W07404, doi:10.1029/2007WR006545, 2008.

Liston, E. G. and Sturm, M.: Winter Precipitation Patterns in Arctic Alaska Determined from a Blowing-Snow Model and SnowDepth Observations, J. Hydrometeorol., 3(4), 646-659, 2002.

López-Moreno, J. I. and Nogués-Bravo, D.: Interpolating local snow depth data: An evaluation of methods, Hydrol. Process., 20, 2217-2232, 2006.

Luce, C. H., Tarboton, D. G., and Cooley, K. R.: Sub-grid parameterization of snow distribution for an energy and mass balance snow cover model, Hydrol. Process., 13, 1921-1933, 1999.

Male, D. H., and Gray, D. M.: Snowcover ablation and runoff, in: Handbook of snow, edited by: Gray, D. M. and Male, D. H., Pergamon Press, Toronto, CA, 360-436, 1981.

Marchand, W. D. and Killingtveit, A.: Statistical properties of spatial snowcover in mountainous catchments in Norway, Nord. Hydrol., 35, 101-117, 2004.

Marty, C.: Regime shift of snow days in Switzerland, Geophys. Res. Lett., 35, L12501, doi:10.1029/2008GL033998, 2008.

Merz, R., Parajka, J., and Blöschl, G.: Scale effects in conceptual hydrological modeling, Water Resour. Res., 45, W09405, doi:10.1029/2009WR007872, 2009.
Mizukami, N. and Perica, S.: Spatiotemporal Characteristics of Snowpack Density in the Mountainous Regions of the Western United States, J. Hydromet., 9, 1416-1426, doi:10.1175/2008JHM981.1, 2008.

Mott, R., Faure, F., Lehning, M., Löwe, H., Hynek, B., Michlmayr, G., Prokop, A., and Schöner, W.: Simulation of seasonal snowcover distribution for glacierized sites on Sonnblick, Austria, with Alpine 3D model, Ann. Glaciol., 49, 155-160, 2008.

Mott, R. and Lehning, M.: Meteorological modelling of very high resolution wind fields and snow deposition for mountains, J. Hydromet., doi:10.1175/2010JHM1216.1, in press, 2010.

Pomeroy, J. W. and Gray, D. M.: Snowcover: Accumulation, Redistribution and Management, National Hydrology Research Institute Science Report No. 7., Saskatoon, Saskatchewan, Canada, 144 p., 1995.

Pomeroy, J. W., Toth, B., Granger, R. J., Hedstrom, N. R., and Essery, R. L. H.: Variation in Surface Energetics During Snowmelt in a Subarctic Mountain Catchment, J. Hydromet., 4, 702-719, 2003.

Prokop, A.: Assessing the applicability of terrestrial laser scanning for spatial snow depth measurements, Cold Reg. Sci. Technol., 54, 155-163, 2008.

Prokop, A., Schirmer, M., Rub, M., Lehning, M., and Stocker, M.: A comparison of measurement methods: Terrestrial laser scanning, tachymetry and snow probing, for the determination of spatial snow depth distribution on slopes, Ann. Glaciol., 49, 210 216, 2008.

Raderschall, N., Lehning, M., and Schär, M.: Fine-scale modeling of the boundary layer with wind field over steep topography, Water Resour. Res., 44, W09425, doi:10.1029/2007WR006545, 2008.

Riegl Laser Measurement Systems, G.: Long-range laser profile measuring system LPM-321: Technical documentation \& user's instructions, 2008.

Rovansek, R. J., Kane, D. L., and Hinzman, L. D.: Improving Estimates of Snowpack Water Equivalent Using Double Sampling, Proceedings of the 61st Western Snow Conference, 8-10 June 1993, Queebeck City, Canada, 1993.

Schaffhauser, A., Fromm, R., Jörg, P., Luzi, G., Noferini, L., and Sailer, R.: Remote sensing based retrieval of snow cover properties, Cold Reg. Sci. Technol., 54, 164-175, 2008.

Skaloud, J., Vallet, J., Keller, K., Veyssière, G., and Kölbl, O.: An Eye for Landscapes - Rapid Aerial Mapping with Handheld Sensors, GPS World, 17, 26-32, 2006.

Trujillo, E., Ramirez, J. A., and Elder, K. J.: Topographic, meteorologic, and canopy controls on the scaling characteristics of the spatial distribution of snow depth fields, Water Resour. Res., 43, W07409, doi:10.1029/2006WR005317, 2007.

Vallet, J. and Skaloud, J.: Helimap: Digital imagery/lidar handheld airborne mapping system for natural hazard monitoring, 6 setmana Geomatica, Barcelona, 1-10 February 2005, 2005.

Xue, M., Droegemeier, K. K., and Wong, V.: The Advanced Regional Prediction System (ARPS) - a multi-scale nonhydrostatic atmospheric simulation model. Part I: Model dynamics and verification, Meteorol. Atmos. Phys., 75, 161-193, 2000. 